\title{
Flow Dimensions on Daily Activities with the Spanish Version of the Flow Scale (DFS)
}

\author{
Sergi Rufi ${ }^{1}$, Federico Javaloy ${ }^{1}$, Joan M. Batista-Foguet ${ }^{2}$, Antonio Solanas ${ }^{1}$ and Darío Páez ${ }^{3}$ \\ 1 Universidad de Barcelona (Spain) \\ ${ }^{2}$ Universidad Ramon Llull (Spain) \\ ${ }^{3}$ Universidad del País Vasco (Spain)
}

\begin{abstract}
A sample of 250 students of psychology with an average age of 20.37 years, answered the Flow Q questionnaire indicating their favorite flow activity, and the Spanish version of the Dispositional Flow Scale (DFS). A confirmatory factor analysis assessed the DFS construct validity of the flow model on daily activities. Both a hierarchical model of eight first order factors reflecting a second order global flow factor, and a model with eight formative first order flow dimensions, showed good fit and discriminant power. Most optimal activities were found to be individual and structured, such as studying, reading and certain forms of individual sports. Leisure activities turned out to be more rewarding than studying. Sports displayed more flow, clear goals, merging of action and awareness, and autotelic experience. Reading also showed more flow, balance of challenge and skills, feedback, merging of action and awareness, and loss of self-consciousness. On the other hand, studying displayed less flow, merging of action and awareness, and autotelic experience.
\end{abstract}

Received 31 July 2012; Revised 18 March 2013; Accepted 10 June 2013

Keywords: flow, flow dimensions, daily optimal activities, formative and reflective analysis models.

Flow is a fundamental psychological state which allows for experiencing a rich and complete life. This phenomenon may appear in any area of life (Csikszentmihalyi, 1990; 1997), and it is related to the satisfaction gained from performing different activities. Csikszentmihalyi \& Csikszentmihalyi (1998) consider that there is an individual predisposition to experiencing this positive state of mind (autotelic personality), and its study has become relevant within the intrinsic motivation and subjective well-being framework. Flow is a positive psychological state that happens when individuals are fully immersed and absorbed in a particularly enjoyable activity. It is an automatic high concentration state of consciousness effortlessly achieved (Csikszentmihalyi, 1996), a holistic sensation that people experience when they are fully engaged in an activity (Csikszentmihalyi, 1975a). Flow state entails attention control, brings order into consciousness and when it is often experienced, enhances the quality of life since it makes the present moment more enjoyable and allows building confidence in order to develop personal skills. Unlike Maslow's peak-experiences, which tend to happen in very special occasions (Maslow, 1964), flow may be found in any area of daily life. It is a universal

Correspondence concerning this article should be addressed to Sergi Rufi. Department de Psicologia Social. Facultat de Psicologia. Universidad de Barcelona. Passeig de la Vall d'Hebron, 171. 08035. Barcelona (Spain). Phone: +34-933125076. Fax: +34-934021359.

E-mail: rufisergi@ub.edu phenomenon (Han, 1988; Massimini \& Carli, 1988; Massimini, Csikszentmihalyi, \& Delle Fave, 1988; Sato, 1998) and a constant feature in all cultures regardless of sociodemographic variables (Prada, 2005). Even though the frequency and intensity of flow experiences vary from person to person, both of these aspects have been associated with personal well-being (Csikszentmihalyi, 1990; 1997; Csikszentmihalyi \& Csikszentmihalyi, 1998; Keller \& Landhäußer, 2012).

Flow theory is part of activity theory (Diener, 1984; Keller \& Landhäußer, 2012; Moneta, 2012), which postulates that well-being is a product of human activity (social interaction, leisure and other activities), and that active involvement is the cause of well-being, which, beyond external outcomes, emerges from an inner process and behavior. Flow theory states that activities become enjoyable once the individual's skills meet the challenge of the task. As such, the individual feels a pleasant experience of fluidity by having his attention focused. Consequently, frequent engagement in interesting activities that capture one's attention is a way of enriching life by making it more complex, which directly affects the quality of life and subjective well-being.

Scientific literature has associated the optimal experience with motivation and attention theories, and its emergence has been studied in different areas, such as academic, work, leisure environments, and more extensively in sports conditions (Keller \& Landhäußer, 2012; Moneta, 2012; Sinnamon, Moran, \& O'Connell, 
2012). In Spanish literature the psychological construct of flow has been broadly studied as a cognitive and affective variable mainly in areas such as athletic performance and physical education (Moreno, CervellóGimeno, \& González-Cutre Coll 2006; Moreno, Conte Marín, Borges Silva, \& González-Cutre Coll 2008; Moreno, Noguera, Coll, Gimeno, \& Pérez, 2009). Furthermore, its effects have also been investigated in motivation and personal skills development within school settings, especially among populations of children and adolescents (Mesurado, 2008; 2009a; 2009b; 2010).

\section{Optimal activities}

Optimal activities are those in which the mind, rather than wandering distracted, gets focused and takes no effort in developing the activity (Pearce, Ainley, \& Howard, 2005) whose performance provides an immediate intrinsic motivation (Csikszentmihalyi, 1975b). In order to produce flow, an activity must offer a goal in line with the individual's skills and provide immediate feedback. However, no activity by itself guarantees the emergence of flow (Csikszentmihalyi \& Csikszentmihalyi, 1998). Its activation not only depends on the characteristics of the activity, but also on personal skills as well as on the perception and attitude that the individual shows toward the task (Mesurado, 2009b). Therefore, an activity itself can never be called "optimal" in the full sense of the word, but only to the extent that it presents characteristics found to be associated with the flow experience. In this sense, Csikszenmihalyi (1990) stated that flow-producing activities were those designed to facilitate concentration and involvement, which made them radically different from the rest of everyday existence.

Thus, optimal activities are connected with a type of positive and rewarding experience, and belong to the realm of the everyday (Delle Fave \& Massimini, 2005). These activities are both mandatory and productive (work and study), and free leisure oriented. They are also both structured (sports and hobbies) and relaxing (watching TV), and their preference and selection varies from one culture to another (Delle Fave \& Bassi, 2009).

In this regard, Csikszentmihalyi \& Csikszentmihalyi (1998) stated that it was more likely that flow resulted from a structured activity (with instructions or fixed rules) than from an unstructured (spontaneous) one. Indeed, spontaneous activities also produce well-being, but less compared to the flow produced by structured tasks (Csikszentmihalyi, 2003; Mesurado, 2009a).

In addition, flow may be experienced both by performing a solo activity and socially; by flowing coactively (in the presence of others) or interactively (in cooperation). Social flow seems to occur more frequently, e.g. $60 \%$ of the activities mentioned in American samples are social or performed in the presence of others (Walker, 2010). Moreover, social flow is associated with greater satisfaction and positive emotions in samples taken from the U.S. and Argentina, than flow in individual activities (Walker, 2010; Mesurado, 2009a). Also, active and structured activities and leisure in general generate higher flow (Mesurado, 2009a).

\section{Theoretical model and flow measurement}

Csikszentmihalyi proposed a flow model consisting of nine dimensions (1990; 1996), three conditions and six characteristics. The fundamental condition, designated as 'universal precondition of flow' (Csikszentmihalyi \& Csikszentmihalyi, 1998) is the balance between the challenge of the task and the skills of the individual. Originally, it was thought that the optimal experience depended mainly on this aspect (Engeser \& Rheinberg, 2008; Keller \& Landhäußer, 2012). In turn, this condition requires goals to be clear and a direct feedback in the action. These requirements are then followed by six characteristics: concentration on the task, actionawareness merging, sense of control, loss of consciousness of the self and merging with the environment, time distortion and intrinsically rewarding (autotelic) experience. Chen, Wigand, and Nilan (1999) and Novak, Hoffman, and Yung (2000) distinguished antecedents, which consist of a clear goal that is a challenge in balance with one's skills and provides direct feedback. The experiences followed are an intense involvement and concentration on the task, the merging of action and awareness and the consequent sense of control over the activity being performed. And finally, flow effects are a loss of self-awareness, the time distortion and a sense of intrinsic enjoyment upon completion of the activity (autotelic experience). For Keller \& Landhäußer (2012) the fit of perceived skills and task demands is the flow antecedent during engagement in a skill-related activity. In their view, there is no chance to perceive the balance of skills and task demands unless one is carrying out a task (clear goal) and already receiving diagnostic information regarding one's progress in the activity (feedback). Then a combination of six experiential states follow, namely a reduced reflective self-consciousness, a modified experience of time, involvement and enjoyment of the activity, a focused concentration, and a strong feeling of control, so the activity is perceived as rewarding in itself.

Csikszentmihalyi's flow model of nine factors was turned into the Flow State Scale (FSS) by Jackson and Marsh (1996) in order to facilitate flow research in sports and physical activity. The FSS contains 36 items and measures flow as a state, and is answered after 
performing the optimal activity (Jackson \& Marsh, 1996). The Dispositional Flow Scale (DFS) takes the Flow Trait Scale (TFS), developed to measure flow as a broad trait during sports participation, and measures the athletes' tendency to experience flow frequently (Jackson, Kimiecik, Ford, \& Marsh, 1998). Later on, several items were amended in order to improve the measurement of some flow dimensions and new versions of both scales were created, FSS-2 and DFS-2 (Jackson \& Eklund, 2002). Research carried out in the U.S., Canada, Australia, Spain, Japan and Portugal have found the reliability of the DFS and FSS nine subscales to be reasonable with the exception of time and self-awareness, which showed lower internal consistency (García-Calvo, Jiménez, Santos-Rosa, Reina, \& Cervelló, 2008; Gouveia, Pais-Ribeiro, Marques, \& Carvalho, 2012; Jackson \& Marsh, 1996; Kawabata, Mallett, \& Jackson, 2008; Marsh \& Jackson, 1999; Tenenbaum, Fogarty, \& Jackson, 1999).

For the Spanish population, flow has mainly been studied in the area of sport (García-Calvo, Cervelló, Jimenez, Iglesias, \& Santos-Rosa, 2005; García Calvo, Cervelló, \& Santos-Rosa, 2006; García Calvo et al., 2008; Moreno et al., 2006; 2008; 2009). In addition, flow has also been studied in school settings by Mesurado (2008; 2009a; 2009b; 2010), who developed and validated the Optimal Experience Questionnaire for children and adolescents.

Dimensional theoretical models of optimal experience and their contrast using confirmatory factor analysis

Throughout flow research different dimensional or structural models have been proposed and evaluated. A first model conceives flow as a single process composed of nine dimensions that make up the phenomenon and it is equivalent to one single factor model (Moneta, 2012). This model adjusts poorly to the data structure and has consistently been rejected (Jackson \& Marsh, 1996; Marsh \& Jackson, 1999; Mesurado, 2009b; Tenenbaum et al., 1999). Mesurado (2009b) postulated a model consisting of two correlated factors. One based on affective and cognitive experiences of flow, and another on a sense of accomplishment and ability to perform the task equivalent to a model of two global factors, and it has not yet been contrasted. Mesurado (2009b) also proposed a model made up of four factors, the perception of ability (control), the perception of achievement, cognitive activation and positive affect. This explanatory model of four factors was the most suitable for the data structure and is in line with the three-stage model of Chen et al. (1999). Lastly, other authors propose to merge antecedents and concentration on the task into one single antecedent factor (Moneta, 2012). These procedural models were not contrasted by structural modeling, although the most recent and authoritative revision on flow concludes that both models -nine independent factors and one single factor- fit the data (Keller \& Landhäußer, 2012).

Finally, a hierarchical model consisting of one global flow factor and nine first-order factors, which suggests that there are nine dimensions influenced by a single underlying process, was postulated and tested (Moneta, 2012), as well as a nine factor model that proposes flow as nine separate dimensions with no underlying global process. These two models have been tested in different populations (United States, anglophone and francophone Canada, Australia, Japan, Greece, Portugal and a Spanish sample by GarciaCalvo et al., in 2008). In samples composed of athletes the hierarchical model (in 4 out of 7 nations), and the nine first-order factors model (in all nations except for Greece) showed an acceptable fit to the data structure, except for the Greek study. In Portugal a hierarchical model of seven factors excluding time and loss of self-consciousness suited to the data structure. Finally, in Japan the hierarchical model was not contrasted (Doganis, Iosifidou, \& Vlachopoulos, 2000; Fournier et al., 2007; Gouveia et al., 2012; Jackson \& Marsh, 1996; Kawabata et al., 2008; Marsh \& Jackson, 1999; Tenenbaum et al., 1999). As far as the Spanish population goes, the hierarchical model was considered the most appropriate (Garcia-Calvo et al., 2008).

The overall objective of the present study is to get to know the flow dimensions on daily activities, according to the Spanish version of the DFS for a sample of non-athlete participants. This may come in the following specific objectives.

The first objective is to know, by using a confirmatory factor analysis, the construct validity of the DFS confirming that the expected flow dimensions correspond to the results of such analysis. It is intended to recover the daily and universal use of flow as Csikszentmihlyi propounded, by applying the Spanish version of the Flow $Q$ and DFS to a variety of human activities beyond specific contexts such as sport, work or educational settings.

The second objective of this study is to find out which model best explains the structural flow dimensions. It involves verifying and contrasting two theoretical alternative specifications. First, a hierarchical or reflective model consisting of a global factor and nine second-order factors (Garcia-Calvo et al., 2008, Jackson \& Marsh, 1996) that assumes that the nine sub-dimensions are manifestations of flow and should covary (by showing the same antecedents and consequences, and similar relationships criteria). Secondly, a formative model of the same construct that arises from the sum of the nine flow components. This model states that the nine facets make up the construct and don't reflect a 
common underlying factor, therefore do not covary in the same way (Bisbe, Batista-Foguet, \& Chenhall, 2007). As mentioned before, both are the most supported models according to cross-cultural studies. Therefore, discussion of the two likely structures of the Flow $Q$ and the DFS is set out in this study. First, by comparing the fit of both models, second, by finding out which specification discriminates better between extreme flow groups. For this purpose, two extreme groups are created in the sample -high flow \& low flow- and differences in flow dimensions are contrasted.

The last objective is to compare the differences between optimal activities regarding each of the dimensions of the flow construct. This will provide better understanding of the specific differences involved in the experience in each of the activities considered to be optimal by the participants.

\section{Method}

\section{Participants}

Participants were 250 psychology students (195 women and 55 men) from the Universidad de Barcelona $(M=20.37, S D=5.54)$.

\section{Instruments}

The Flow Questionnaire (Csikszentmihalyi, 1982; Csikszentmihalyi \& Csikszentmihalyi, 1998) was translated into Spanish following Brislin's (1980) translation-back-translation procedure. This questionnaire proposes flow definitions and asks respondents to recognize them as well as activities where they experience flow. The FQ examines the broad sense of the optimal experience given by Csikszentmihlyi.

The Spanish version of the Dispositional Flow Scale (DFS) (Jackson et al., 1998) based on the Spanish translation of the Flow State Scale (FSS) (Jackson \& Marsh, 1996) and developed by García-Calvo et al. (2008). Both are 36-item scales that explore the nine flow dimensions and distinguish themselves by the instructions given to participants, whereas the FSS asks participants to answer the questions of the specific activity they just completed. The DFS asks participants to answer the questions thinking of their general experience regarding the activity they have freely chosen (Moneta, 2012).

\section{Procedure}

The instruments were distributed in different sessions during the second and third week of April 2011 between students attending a Social Psychology lesson. The administration of the questionnaires was conducted in the presence of the principal investigator who informed students on how to properly complete them.
The confidentiality of participants' data was fulfilled through anonymity. The time required to complete the questionnaires was around 15 minutes. Students first noted down the activity they considered optimal based on the flow descriptions on the Flow $Q$, and then answered the DFS according to the activity.

\section{Data Analysis}

SPSS Statistics 21 was used to obtain the necessary information for answering the various research questions identified in this study. First, a few descriptives characterized the sample of participants in the study. Then, an Exploratory Factor Analysis (EFA) provided an indication of the number of flow dimensions to be reasonably considered, while Confirmatory Factor Analysis (CFA) allowed us to test two possible specification structures, the reflective and formative models. Finally, different statistical inferential techniques were used in order to determine the daily activity profiles considering the flow factors.

\section{Results}

\section{Descriptives}

Of the sample $(N=250), 75.7 \%(N=190)$ claimed to have ever experienced flow. The activities described were classified by two of the authors ( $95 \%$ agreement) based on the activity being performed individually, in the presence of others or in interaction with others, as well as if the activity was structured or not. While playing sports $19.5 \%$ of the participants $(N=49)$ claimed to experience flow, compared to $13.5 \%(N=34)$ while studying, 9.2\% $(N=23)$ while reading and $5.2 \%$ $(N=13)$ while playing an instrument. Individual flow activities were picked by $64.6 \%(N=122)$ while social activities were picked by $35.4 \%(N=67)(23.8 \%$ interactive \& 11.6 co-active). Lastly, the activities included within the 'structured activity' category were: playing sports, studying, playing an instrument, dancing, work, playing games, meditating and doing yoga and theater. The 'unstructured activities' were: reading, listening to music, drawing, watching TV, writing, walking and socializing. In this regard, $71 \%$ of the participants chose a flow structured activity versus $29 \%$ who picked an unstructured flow task.

\section{Exploratory Factor Analysis}

Of the participants, the $24.3 \%$ that claimed to never have experienced flow (the non-flowers) were not included in the factor analysis. The analysis was conducted taking into consideration only the flowers, $75.7 \%$ of the participants. First, we carried out an EFA to test whether the expected nine-factor structure of flow prevails in our sample of psychology students. 
In fact, this nine-factor structure was corroborated in a previous study on the Spanish population with a sample consisting of solely athletes (Garcia-Calvo et al., 2008). Yet, in the present study, participants were students of psychology and no evidence showed that the subpopulations were comparable. It was used Maximum Likelihood estimation (IBM SPSS Statistics 21) which led to extract 8 factors with eigenvalues above 1 that accounted for $72.7 \%$ of the total variance.This initial analysis revealed that instead of the expected nine flow factors only eight emerged. Specifically, the results showed clearly that for our sample, the flow dimensions balance and feedback were joined together. This feature, which may be attributed to the characteristics of the sample used, convinced us to merge these two dimensions into a single factor and specify a Flow model with eight flow dimensions.

Then, our Promax (Oblique rotation) in the EFA led to some correlations among factors that were negligible (time-goal-balance, autotelic-self-awareness, merging-control). In addition, these detected correlations were clearly non-significant in our subsequent CFA model which let free the correlations among the eight latent dimensions (see Table 1). As a consequence, when we did constrain these correlations to be zero neither chi-square nor any other global fit index showed significant increments. Therefore, we interpret that at least in our sample Flow could not be understood as a second order factor from our eight first order factors, but some of the Flow dimensions have to be deemed more as formative Flow factors, rather than reflective ones.

\section{Confirmatory Factor Analysis}

In order to test the measurement model we used CFA freeing the covariances among the latent 8 dimensions to be estimated. We used Maximum likelihood estimation on the covariance matrix with standard software (LISREL 8.72) in order to get the estimates of the different parameters. The data had almost no missing values, with the percentage of missing values for each variable being less than $1 \%$. Consequently, these missing values were considered to be at random and were imputed using SPSS maximum likelihood (IBM SPSS Statistics 21).

The confirmatory factor analysis (CFA) model without letting any error correlation to be freely estimated yielded a Satorra-Bentler Chi-Square (with 535 degrees of freedom $)=685.8(p<.0001)$, the Root Mean Square Error of Approximation (RMSEA) $=0.0386$, and its $90 \%$ Confidence Interval $=(0.0294 ; 0.0469)$, and a Comparative Fit Index $(\mathrm{CFI})=0.987$, which indicates not such a bad fit as one may think. When the error correlations were freely estimated, the magnitudes of these estimated correlations were very small, which, as mentioned before in the text (p. 14), led us to interpret that our case involved a situation of relatively high power. As a consequence, the rejection of the model would be inconclusive and due to very small misspecifications. That is, it is too sensitive for specific misspecifications (Saris, Satorra, \& Van der Veld, 2009).

In SEM, the interpretation of results does not proceed until the goodness of fit has been assessed. However, the present case involves a situation of relatively high power and, although sample size is not considerable $(N=190)$, high reliability of the indicators is achieved (please refer to Table 2) and the model is relatively parsimonious with four indicators per latent dimension. As a consequence the rejection of the model would be inconclusive.

Nevertheless, after releasing plausible restrictions on some correlations among unique components of our CFA model, the usual global fit indexes reported a fairly good fit. Actually, the final measurement model yielded a Satorra-Bentler Chi-Square (with 519 degrees of freedom $)=567.937(p=.068)$; the RMSEA $=.0223$ and its $90 \%$ Confidence Interval $=(.0 ; .0336)$ with $p$-value for Test of Close Fit $($ RMSEA < .05) $=.312$ and a $\mathrm{CFI}=.996$, which indicates a very good fit.

Even when every global fit index is within the appropriate thresholds, these indexes may have important drawbacks and can lead to wrong conclusions (see Barret, 2007 and the special issue on Structural Equation Modeling in Personality and Individual Differences, 2007). Therefore, in this diagnosing stage Kline's (2010, p. 321) advice on the "fit index tunnel vision" was considered, which stands for "looking only at indexes of overall model fit and ignoring other types of information about fit [...] a disorder that is fortunately curable by looking through the entire output (detailed diagnosis)".

This is actually in line with the recent proposal by Saris et al. (2009) that recommended paying more attention to the detection of misspecification errors rather than focusing solely on the global fit and taking into account not only the significance levels but also the power of the test. As has been mentioned, since the initial model lead to some misspecifications, according to Saris et al.'s (2009) procedure, few plausible constraints on uncorrelated uniqueness were released, and as a result the model fits the data well. All loadings have estimated values which are reasonable and with the expected sign. There are no significant residuals that suggest the addition of other parameters.

Once flow scores were obtained considering both perspectives -the reflective (or hierarchical) and formative (or eight relatively independent dimensions)-, the discriminant power of DFS was assessed. For this purpose, extreme groups of the sample $-25 \%$ inferior and 
Table 1. Factor loadings of the Confirmatory Factor Analysis of the Spanish Version of the Flow Scale

\begin{tabular}{llllllllllll}
\hline Item & A-C & C-G & A-E & L-S & D-T & A-A & C-T & S-C
\end{tabular}

1. Sabía que mi capacidad me permitiría hacer frente al desafío que se me planteaba.

10. Mi habilidad estaba al mismo nivel de lo que me exigía la situación.

19. Sentía que era lo suficientemente bueno para hacer frente a la dificultad de la situación.

28. Las dificultades y mis habilidades para superarlas, estaban a un mismo nivel.

4. Tenía realmente claro que lo estaba haciendo bien.

13. Sabía lo bien que lo estaba haciendo.

22. Tenía buenos pensamientos acerca de lo bien que lo estaba haciendo mientras estaba practicando.

31. Estaba seguro de que en ese momento, lo estaba haciendo muy bien.

3. Conocía claramente lo que quería hacer.

12. Estaba seguro de lo que quería hacer.

21. Sabía lo que quería conseguir.

30. Mis objetivos estaban claramente definidos.

9. Realmente me divertía lo que estaba haciendo.

18. Me gustaba lo que estaba experimentando en ese momento y me gustaría sentirlo de nuevo.

27. La experiencia me dejó un buen sabor de boca (buena impresión).

36. Encontré la experiencia muy valiosa y reconfortante.

7. No me importaba lo que los otros podían haber estado pensando de mí.

25. No estaba preocupado por la imagen que daba a los demás.

34. No me preocupaba lo que otros pudieran estar pensando de mí.

8. El tiempo parecía diferente a otras veces (ni lento, ni rápido).

17. El paso del tiempo parecía ser diferente al normal.

26. Sentía como si el tiempo se parase mientras estaba practicando.

35. A veces parecía que las cosas estaban sucediendo como a cámara lenta.

2. Hice los gestos correctos sin pensar, de forma automática.

11. Parecía que las cosas estaban sucediendo automáticamente.

20. Ejecutaba automáticamente.

29. Hacía las cosas espontánea y automáticamente.

5. Mi atención estaba completamente centrada en lo que estaba haciendo.

14. No me costaba mantener mi mente en lo que estaba sucediendo.

23. Tenía una total concentración.

32. Estaba totalmente centrado en lo que estaba haciendo.

6. Sentía un control total de lo que estaba haciendo.

15. Sentía que podía controlar lo que estaba haciendo.

24. Tenía un sentimiento de control total.

33. Sentía un control total de mi cuerpo.

\section{.637}

.639

.775

.704

.684

.826

.649

.790
.726
.827
.964
.928 .729

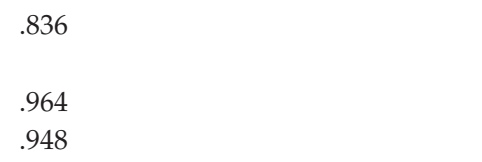

.897

.869

.774

.504

Note: A-C = Balance between ability level and challenge C-G = Clear goals A-E = Autothelic experience L-S = Loss of self-consciousness D-T $=$ Distorted sense of time A-A = Merging of action and awareness C-T = Concentration on task $\mathrm{S}-\mathrm{C}=$ Sense of control. 
Table 2. Correlations among the underlying dimensions

\begin{tabular}{|c|c|c|c|c|c|c|c|c|}
\hline & A-C & C-G & A-E & L-S & $\mathrm{D}-\mathrm{T}$ & A-A & $\mathrm{C}-\mathrm{T}$ & $\mathrm{S}-\mathrm{C}$ \\
\hline Balance between ability level and challenge & - & & & & & & & \\
\hline Clear goals & .573 & - & & & & & & \\
\hline Autothelic experience & .285 & .255 & - & & & & & \\
\hline Loss of self-consciousness & .210 & $.000\left(^{*}\right)$ & .123 & - & & & & \\
\hline Distorted sense of time & .000 & .000 & .421 & .192 & - & & & \\
\hline Merging of action and awareness & .485 & .249 & .420 & .163 & .311 & - & & \\
\hline Concentration on task & .403 & .414 & .604 & .231 & .220 & .375 & - & \\
\hline Sense of control & .838 & .546 & .297 & .253 & .000 & .385 & .410 & - \\
\hline
\end{tabular}

Note: A-C = Balance between ability level and challenge C-G = Clear goals A-E = Autothelic experience L-S = Loss of self-consciousness D-T $=$ Distorted sense of time A-A = Merging of action and awareness $\mathrm{C}-\mathrm{T}=$ Concentration on task $\mathrm{S}-\mathrm{C}=$ Sense of control.

$\left.{ }^{*}\right)$ the uncorrelated factors null hypotheses cannot be rejected.

$25 \%$ superior- were used according to the global dimension of flow for both conceptualizations. When comparing the means of the extreme groups with a $t$-test for independent data, the results showed that for both definitions the differences were significant, $p$-values range from.001 to .002. When comparing the means values for the different flow components (e.g. loss of self), it was revealed that for both specifications, the high-flow group showed a higher mean than the low-flow group in all cases. Therefore, the results were identical regardless of how the global flow dimension was conceptualized. Furthermore, the results were consistent with the conjecture that the global dimension of flow is a composite of its constituents acting in the same direction.

Regarding the association between the level of global flow considering the extreme groups and the type of optimal activity, the results showed a clear statistical association considering both the reflective and the formative definitions. Specifically, for the reflective model of the global flow $\left[\chi^{2}(7, N=190)=15.57\right.$, $p=.016]$, individuals from the high-flow group seemed to flow more often while practicing sports (36.8\%) and reading $(26.3 \%)$, whereas individuals from the lowflow group felt an optimal experience while studying $(37.8 \%)$. Considering the formative model, the results were relatively similar. The high-flow group found flow mainly by practicing sports $(37.8 \%)$ and reading $(18.9 \%)$, whereas the low-flow group mostly while studying $(44.4 \%)\left[\chi^{2}=(7, N=190)=17.42, p=.008\right]$. Again, analysis of the global dimension of flow taking into account the type of optimal activity led to similar results for both the reflective and the formative model.

Finally, regarding the factors constituting the dimension of global flow, means were obtained for the different activities considering the entire sample (Table 3). The intention was to figure out the different profiles for each type of optimal activity. To get an idea of the relative importance of each dimension, direct scores were calculated for each flow dimension (antecedents, processes and effects). The direct scores showed that the global mean was $M=7.93, S D=1.03$. Flow antecedents had a score slightly below the global mean score, $M=7.77, S D=1.32$, and student's $t$ for paired samples was 2.87, $p<.005$. Flow processes showed a score slightly above, $M=8.01, S D=1.14$, and student's $t$ for paired samples was $2.38, p<.02$. Lastly, flow effects had a score equal to the global mean $M=8.0, S D=1.26$ and student's $t$ for paired samples was $2.29, p<.01$. It is important to take into account that factor scores are expressed in deviations from the mean score, being a score of +.35 about a score of 8.4. Since the homoscedasticity test indicated that equal variances could not be assumed for the seven populations considered (i.e. the different optimal activities), a nonparametric Kruskal-Wallis $\mathrm{H}$ test was used. For the factor scores obtained in the reflective model, statistical significance was obtained for the following factors: balance and feedback $\chi^{2}(6, N=190)=12.76, p=.05$, goal $\chi^{2}(6, N=$ $190)=13.45, p=.036$, merging $\chi^{2}(6, N=190)=14.45$, $p=.025$ and autotelic $\chi^{2}(6, N=190)=34.92, p<.001$. When the same statistical analysis was performed for the formative specification, statistical significance was obtained for the following factors: balance and feedback $\chi^{2}(6, N=190)=13.68, p=.033$, merging $\chi^{2}(6, N=190)$ $=16.38, p=.012$, self-consciousness $\chi^{2}(6, N=190)=$ $14.21, p=.027$ and autotelic $\chi^{2}(6, N=190)=31.96, p<.001$. As shown, the results are very similar regardless of whether considering the eight dimensions under a reflective or a formative conceptualization.

The comparison of factor means showed that the balance and feedback are lower while studying and performing artistic activities, average while practicing sports, and higher when reading. The goal is higher in experiences involving coordinated activity and body movements such as sports, playing an instrument and 
Table 3. Optimal activities description according to the Flow Dimensions (Reflexive Model)

\begin{tabular}{|c|c|c|c|c|c|c|c|}
\hline Flow Dimensions & Sports & Study & Reading & $\begin{array}{l}\text { Listening to } \\
\text { music }\end{array}$ & $\begin{array}{l}\text { Playing an } \\
\text { instrument }\end{array}$ & Drawing & Dance \\
\hline $\begin{array}{l}\text { Balance between ability level and } \\
\text { challenge }\end{array}$ & .14 & -.24 & .41 & -.14 & -.11 & -.24 & -.07 \\
\hline Clear goals & .35 & .10 & -.04 & -.20 & .33 & -.91 & .33 \\
\hline Autothelic experience & .38 & -.80 & .02 & .30 & .41 & .15 & .44 \\
\hline Loss of self-consciousness & -.06 & .06 & .25 & .04 & -.81 & -.71 & -.01 \\
\hline Distorted sense of time & .08 & -.38 & .22 & .12 & .00 & -.20 & .39 \\
\hline Merging of action and awareness & .25 & -.36 & .25 & .21 & -.52 & -.22 & .15 \\
\hline Concentration on task & .04 & -.29 & .26 & -.20 & .19 & .24 & .39 \\
\hline Sense of control & .17 & -.17 & .14 & .28 & -.28 & -.03 & .11 \\
\hline
\end{tabular}

Note: Flow Dimensions displayed in accordance with Chen, Wigand y Nilan (1999)'s classification.

dancing, and lower while drawing and listening to music. With regard to flow processes, no significant differences in concentration and control were found between activities. Although significant differences were found in the merging dimension, this procedural aspect of the flow experience is higher when practicing sports, reading and listening to music, and lower while studying and playing instruments. Finally, differences were found in self-consciousness, which is higher while reading and studying, and lower when playing instruments and drawing, and autotelic, which is higher while dancing, playing instruments and practicing sports, and lower when studying.

\section{Discussion}

As the results show, the positive experience of flow is present in the consciousness of most participants when performing their favorite everyday activities $(75.7 \%)$. As a result, it seems safe to state that for the Spanish population flow is a relevant psychological process that affects not only athletes (Garcia-Calvo et al., 2008), but is also experienced in other areas of everyday life (Csikszentmihalyi, 1990; 1997). Specifically, most participants found flow experiences while engaging in solitary activities (64.6\%), compared to a minority (35.4\%) who tended to flow when performing social activities. This ratio is in line with research conducted by Dean (2009), where most of the sample $(88.4 \%)$ claimed to experience flow in non-social activities yet seems inconsistent with other results (Walker, 2010). Both the results of the research carried out by Dean and the present study note that solitary experiences are more important sources of flow than social experiences. This statement a priori seems to contradict the claims that optimal experiences are more frequently experienced in social contexts (Mesurado, 2009a). However, it seems not at odds with the claim that social flow is more enjoyable than individual flow (Walker, 2010). Lastly, out of the four most important optimal activities reported three were structured (containing pre-established rules); playing sports, studying and playing an instrument, with reading being the only unstructured one. These results may assert that structured activities tend to produce more flow than spontaneous tasks (Csikszentmihalyi, 2003; Csikszentmihalyi \& Csikszentmihalyi, 1998; Mesurado, 2009a).

The results of the exploratory factor analysis show that the Spanish version of the DFS applied to a sample of psychology students has a factorial structure consisting of eight factors contributing to the total variance of $72.7 \%$. These factors are: the balance of challenge and skills and feedback (merged together), clear goals, autotelic experience, loss of self-consciousness, time distortion, action-awareness merging, concentration on the task and the feeling of control. These results differ slightly from those reported by García-Calvo et al. (2008), where the FSS was applied to a population of athletes. In that study the FSS was composed of the original nine flow factors. The difference of one flow factor between both studies may lie in the nature of the missing factor, the feedback. In the study by Garcia-Calvo et al. (2008), the feedback seemed to be much more direct and clear as the activities consisted entirely of sports, which are clearly structured tasks with fixed rules that provide clear feedback throughout each step of the task. On the other hand, the present study is willing to cover daily activities consisting of both regulated (structured) activities where the presence of feedback is relevant, and spontaneous (unstructured) such as listening to music, watching TV or reading. With unstructured activities feedback is not a relevant element for the individuals to readjust the intention of their actions. Consequently, the type of activity may be the feature regulating the presence of feedback, at times being more prominent at times kind of blurred. 
With regard to structural flow models, the present study contrasted two theoretical possibilities. The reflective model, consisting of a global factor and secondorder factors (Garcia-Calvo et al., 2008; Jackson \& Marsh, 1996), and the formative model of the same construct that emerges from the sum of the eight flow first order components. No significant differences were found when extreme groups were used to determine discriminant power for both models' specifications. Thus, the results show that both models may explain with similar accuracy the structure of the general flow construct in a manner consistent with the studies reviewed. However, the present study highlights that the general flow factor can be may have at least two different conceptualizations. In other words, is the general flow factor an underderlying structure that has an influence on all of its sub-components? Or can the general flow factor be also understood as an aggregate of all its subcomponents? It seems possible to consider flow not as a unitary phenomenon reflected in nine aspects, but a phenomenon with relatively independent components. Some of these would be antecedents, others the psychological effects of the processes and others the psychological outcomes depending on the antecedents, the processes, the type of activity and the participants' psychosocial characteristics. The present study supports that both theoterical conceptions of flow are admissible if empirical results are considered. Hence, the reflective model should not be unconditionally considered to the detriment of the formative model. As a consequence, a theoretical debate should be initiated to decide the most appropriate conception of the general flow factor.

In agreement with Keller and Landhäußer (2012), it is fair to conclude that both models similarly fit the data. Having said that, as Moneta (2012) partially suggests and following Chen et al. (1999), from a theoretical perspective we believe that a process model of three factors is more productive. A model represented by a first latent factor of flow antecedents (balance, goal and feedback), a second factor of flow subjective processes conducive to flow (concentration, merging and control) and its final psychological effects (self-consciousness, time and autotelic). This is a perspective that should be applied in the future by using structural equation modeling, and to our knowledge no empirical contrast has been done yet.

Taking into account this approach, with respect to flow antecedents the comparison of means between activities showed differences in balance and feedback, and goal. Balance and feedback were lower while studying and performing artistic activities; medium when practicing sports; and higher when reading. These results were unexpected regarding reading, although in the case of sports, dancing and playing an instrument (second, third and fourth means in range) they reflected the active nature of such experiences. Goal was higher in experiences involving coordinated activity and body movements such as sports, playing musical instruments and dancing, and lower while drawing and to a lesser extent while listening to music. These results feature the structured and active aspects of the former activities, as well as the passive and unstructured characteristics of listening to music. Results indicate differences in the antecedents intensity showing activities where the balance, feedback, and goal seem to be medium-high (sports), and activities where flow antecedents are low (listening to music) or very low (drawing). Also, whereas the opposition between playing sports and listening to music seems quite reasonable, it is worth noting that an active yet little structured experience like drawing shows the lowest flow antecedents. Moreover, other activities seem to be high only in goal (such as playing an instrument and dancing) or in balance and feedback (such as reading). It seems quite contradictory that playing an instrument or dancing does not deliver a direct feedback, whereas an unstructured task like reading provides clear behavioral direction.

Regarding flow processes, similar responses in concentration and control between activities suggest that they are a stable core of the flow experience. Significant differences are found in merging flow component. This procedural aspect of flow is higher while practicing sports, reading and listening to music, and lower while studying and playing instruments. A higher flow process in sport and lower in study seems reasonable, yet the fact that the merging is higher in passive activities such as reading and listening to music, and lower in structured activities involving conscious and voluntary actions like playing an instrument seems debatable.

With regard to the psychological flow effects, there are differences found for self-consciousness and autotelic, but not for time. Probably concentration and control in terms of processes and time as a psychological effect constitute the stable core of the flow experience. Selfconsciousness seems to be higher while reading and studying, and lower when playing music and drawing. This may be caused by the fact that absorption in symbolic stimuli helps in losing consciousness of the self, while voluntary and conscious activities require an active self. On the other hand, autotelic results are higher in leisure than in work, since dancing, playing an instrument or practicing sports bring in stronger gratification and positive emotions than studying offers.

In summary, high flow is associated with practicing sports and reading and low flow with studying. The association between high flow and sports is explained by the goal, the merging and an autotelic 
experience, and a medium-high balance and feedback. The association between high flow and reading is explained by a high balance and feedback, and a high merging and self-consciousness, yet not due to the goal. Lastly, the association between low flow and studying is explained by the low merging and little intrinsic reward (autotelic) - although self-consciousness dimension is high.

To conclude, the present study provides evidence to support the concurrent validity of the Spanish version of the DFS in relation to the Flow $Q$ to study flow experiences in any given human activity beyond sports. It provides a new line of research intended to explore and compare the profiles of people who flow with more and less intensity. It also offers the possibility to analyze and compare daily activities that report personal well-being by utilizing the flow dimensions separately. Lastly, this study contributes to flow research but has three main limitations. The first one being that it is a correlational study based on retrospective data, thus no causal statements could be pointed out. Secondly, the sample is relatively small since respondents freely chose the optimal activity, therefore variation in factor structure across activities might have occurred. And lastly, testing different models on different types of activities was not allowed due to low degrees of freedom. We believe that with a larger and more diverse sample the present results could be corroborated. Likewise, the hypotheses that different levels and different factor loadings on the latent variable could emerge on different activities could also be tested.

\section{References}

Barret P. (2007). Structural equation modelling: Adjudging model fit. Personality and Individual Differences, 42, 815-824. http:/ /dx.doi.org/10.1016/j.paid.2006.09.018

Bisbe J., Batista-Foguet J. M., \& Chenhall R. (2007). Defining management accounting constructs: A methodological note on the risks of conceptual misspecification. Accounting, Organizations and Society, 32, 789-820. http:/ / dx.doi.org/10.1016/j.aos.2006.09.010

Brislin R. W. (1980). Translation and content analysis of oral and written materials. In H. C. Triandis \& J. W. Berry (Eds.), Handbook of cross-cultural psychology (Vol. 2, pp. 137-164). Boston, MA: Allyn and Bacon.

Chen H., Wigand R. T., \& Nilan M. S. (1999). Optimal experiences of web activities. Computers in Human Behavior, 15, 585-608. http:/ /dx.doi.org/10.1016/ S0747-5632(99)00038-2

Csikszentmihalyi M. (1975a). Beyond boredom and anxiety: Experiencing flow in work and play. San Francisco, CA: Jossey-Bass.

Csikszentmihalyi M. (1975b). Play and intrinsic rewards. Humanistic Psychology, 15, 41-63.
Csikszentmihalyi M. (1982). Toward a psychology of optimal experience. In L. Wheeler (Ed.), Review of personality and social psychology, Vol. 2 (pp. 13-35). Beverly Hills, CA: Sage Publications.

Csikszentmihalyi M. (1990). Flow: The psychology of optimal experience. New York, NY: Harper\&Row.

Csikszentmihalyi M. (1996). Creativity: Flow and the psychology of discovery and invention. New York, NY: Harper Collins.

Csikszentmihalyi M. (1997). Finding flow: The psychology of engagement with everyday life. New York, NY: Harper Perennial.

Csikszentmihalyi M. (2003). Materialism and the evolution of conscious-ness. In T. Kasser \& A. D. Kanner (Eds.), Psychology and consumer culture: The struggle for a good life in a materialistic world (pp. 91-106). Washington, DC: The APA Press.

Csikszentmihalyi M., \& Csikszentmihalyi I. (1998). Experiencia óptima. Estudios psicológicos del flujo en la conciencia. [Optimal experience: Pyschological studies of flow in consciousness]. Bilbao, Spain: Desclée De Brouwer.

Dean B. M. (2009). Optimal experience in relationships, activities, and beyond: Connecting flow with self-expansion. (Unpublished doctoral dissertation). Indiana State University, IN, USA.

Delle Fave A., \& Bassi M. (2009). Sharing optimal experiences and promoting good community life in a multicultural society. The Journal of Positive Psychology, 4, 280-289. http:/ /dx.doi.org/10.1080/17439760902933716

Delle Fave A., \& Massimini F. (2005). The investigation of optimal experience and apathy: Developmental and Psychosocial Implications. European Psychologist, 10, 264-274.

Diener E. (1984). Subjective well-being. Psychological Bulletin, 95, 542-575. http:/ / dx.doi.org/10.1037/ / $0033-$ 2909.95.3.542

Doganis G., Iosifidou P., \& Vlachopoulos S. (2000). Factor structure and internal consistency of the Greek version of the Flow State Scale. Perceptual \& Motor Skills, 91, 1231-1240. http:/ /dx.doi.org/10.2466/pms.2000.91.3f.1231

Engeser S., \& Rheinberg F. (2008). Flow, performance and moderators of challenge-skill balance. Motivation and Emotion, 32, 158-172. http://dx.doi.org/10.1007/ s11031-008-9102-4

Fournier J., Gaudreau P., Dernontrond-Behr P., Visiolic J., Forest J., \& Jackson S. (2007). French translation of the Flow State Scale-2: Factor structure, cross-cultural invariance, and associations with goal attainment. Psychology of Sport and Exercise, 8, 897-916. http:/ /dx.doi. org/10.1016/j.psychsport.2006.07.007

García-Calvo T., Cervelló E. M., Jiménez R., Iglesias D., \& Santos-Rosa F. J. (2005). La implicación motivacional de jugadores jóvenes de fútbol y su relación con el Estado de Flow y la satisfacción en competición. [Motivational involvement of young soccer players, and its relationship with the Flow state and satisfaction in competition]. Revista de Psicología del Deporte, 14, 21-42.

García-Calvo T., Cervelló E. M., \& Santos-Rosa F. J. (2006). Flow y deporte. [Flow and Sport]. In E. J. Garcés de los Fayos, A. Olmedilla, \& P. Jara (Eds.), Psicología y deporte. [Psychology and Sport]. Murcia, Spain: Diego Marín. 
García-Calvo T., Jiménez R., Santos-Rosa Ruano F. J., Reina R., \& Cervelló E. M. (2008). Psychometric Properties of the Spanish version of the Flow State Scale. The Spanish Journal of Psychology, 11, 660-669.

Gouveia M. J., Pais-Ribeiro J. L., Marques M., \& Carvalho C. (2012). Measuring dispositional flow in exercise. Validity and reliability of a Portuguese version of the Dispositional Flow Scale-2 (DFS-2). Revista de Psicología del Deporte, 21, 81-88.

Han S. (1988). The relationship between life satisfaction and flow in elderly Korean immigrants. In M. Csikszentmihalyi \& I. S. Csikszentmihalyi (Eds.), Optimal experience: Psychological studies of flow in consciousness (pp. 138-149). New York, NY: Cambridge University Press. http:/ / dx. doi.org/10.1017/CBO9780511621956.008

Jackson S. A., \& Eklund R. C. (2002). Assessing flow in physical activity: The Flow State Scale-2 and Dispositional Flow Scale-2. Journal of Sport and Exercise Psychology, 24, 133-150.

Jackson S. A., Kimiecik J. C., Ford S., \& Marsh H. W. (1998). Psychological correlates of flow in sport. Journal of Sport and Exercise Psychology, 20, 358-378.

Jackson S. A., \& Marsh H. W. (1996). Development and validation of a scale to measure optimal experience: The Flow State Scale. Journal of Sport and Exercise Psychology, 18, 17-35.

Kawabata M., Mallett C. J., \& Jackson S. A. (2008). The Flow State Scale-2 and Dispositional Flow Scale-2: Examination of factorial validity and reliability for Japanese adults. Psychology of Sport and Exercise, 9, 465-485. http:/ / dx.doi.org/10.1016/j.psychsport.2007.05.005

Keller J., \& Landhäußer A. (2012). The Flow model revisited. In S. Engesar (Ed.), Advances in Flow Research (pp 51-64). New York, NY: Springer Verlag.

Kline R. B. (2010). Principles and practice of structural equation modeling. (3 ${ }^{\text {rd }}$ Ed.). New York, NY: Guildford Press.

Marsh H. W., \& Jackson S. A. (1999). Flow experience in sport: Construct validation of multidimensional, hierarchichal state and trait respones. Structural Equation Modeling, 6, 343-371.

Maslow A. (1964). Religions, values and peak-experiences. Columbus, OH: Ohio State University Press.

Massimini F., \& Carli M. (1988). The systematic assessment of flow in daily experience. In M. Csikszentmihalyi, \& I. S. Csikszentmihalyi (Eds.), Optimal experience: Psychological studies of flow in consciousness (pp. 266-287). New York, NY: Cambridge University Press. http:/ /dx.doi.org/10.1017/ CBO9780511621956.016

Massimini F., Csikszentmihalyi M., \& Delle Fave A. (1988). Flow and biocultural evolution. In M. Csikszentmihalyi \& I. S. Csikszentmihalyi (Eds.), Optimal experience: Psychological studies of flow in consciousness (pp. 60-82). New York, NY: Cambridge University Press. http:/ /dx.doi.org/10.1017/ CBO9780511621956.004

Mesurado B. (2008). Validez factorial y Fiabilidad del cuestionario de Experiencia Óptima (Flow) para niños y adolescentes. [Factor validity and reliability of the Optimal Experience questionnaire for children and adolescents]. Revista Iberoamericana de Diagnóstico y Evaluación Psicológica, 25, 159-178.

Mesurado B. (2009a). Actividad estructurada vs actividad desestructurada, realizadas en solitario vs en compañía de otros y la experiencia óptima. [Structured vs unstructured activity, performed alone vs with other people, and optimal experience]. Anales de Psicología, 20, 308-315.

Mesurado B. (2009b). Comparación de tres modelos teóricos explicativos del constructo experiencia óptima o flow. [Comparison of three theoretical models of the optimal experience or flow construct]. Interdisciplinaria, 26, 121-137.

Mesurado B. (2010). La experiencia de Flow o Experiencia Óptima en el ámbito educativo. [Flow or Optimal Experience in education]. Revista Latinoamericana de Psicología, 42, 183-192.

Moneta G. B. (2012). On the measurement and conceptualization of flow. In S. Engeser, (Ed.), Advances in Flow Research (pp 23-50). New York, NY: Springer Verlag.

Moreno J. A., Cervelló Gimeno E., \& González-Cutre Coll D. (2006). Motivación autodeterminada y flujo disposicional en el deporte. [Self-determined motivation and dispositional flow in sport]. Anales de Psicología, 22, 310-317.

Moreno J. A., Conte Marín L., Borges Silva F., \& GonzálezCutre Coll D. (2008). Necesidades psicológicas básicas, motivación intrínseca y propensión a la experiencia autotélica en el ejercicio físico. [Basic psychological needs, intrinsic motivation and autotelic experience propensity in physical exercise]. Revista Mexicana de Psicología, 25, 305-312.

Moreno J., Noguera F., Coll D., Gimeno E., \& Pérez L. (2009). Flow disposicional en salvamento deportivo: Una aproximación desde la teoría de la autodeterminación. [Dispositional flow in lifesaving sport: A Self Determination Theory approach]. Revista de Psicología del Deporte, 18, 23-35.

Novak T. P., Hoffman D. L., \& Yung Y-F. (2000). Measuring the customer experience in online environments: A structural modeling approach. Marketing Science, 19, 22-42. http:/ / dx.doi.org/10.1287/mksc.19.1.22.15184

Pearce J. M., Ainley M., \& Howard S. (2005). The ebb and flow of online learning. Computers in Human Behavior, 21, 745-771. http:/ /dx.doi.org/10.1016/j.chb.2004.02.019

Prada E. (2005). Psicología positiva y emociones positivas. [Positive psychology and positive emotions]. Revista electrónica Psicología Positiva.com. Retrieved from http://www.psicologia-positiva.com/Psicologiapos.pdf

Saris W. E., Satorra A., \& Van der Veld W. M. (2009). Testing structural equation models or detection of misspecifications? Structural Equation Modeling: A Multidisciplinary Journal, 16, 561-582. http:/ /dx.doi. org /10.1080/10705510903203433

Sato I. (1998). Bosozoku: Flujo en las bandas japonesas motorizadas. [Bosozoku: Flow in Japanese motorcycle gangs]. In M. Csikszentmihalyi \& I. S. Csikszentmihalyi (Eds.), Experiencia Óptima. Estudios psicológicos del flujo en la conciencia. [Optimal experience: Pyschological studies of flow in consciousness]. (pp. 99-120). Bilbao, Spain: Desclée De Brouwer.

Sinnamon S., Moran A., \& O'Connell M. (2012). Flow among musicians: Measuring peak experiences of student. Journal of Research in Music Education, 60, 6-25. http:/ / dx.doi.org/10.1177/0022429411434931

Tenenbaum G., Fogarty G., \& Jackson S. (1999). The flow experience: A Rasch Analysis of Jackson's Flow State Scale. Journal of Outcome Measurement, 3, 278-294.

Walker C. J. (2010). Experiencing flow: Is doing it together better than doing it alone? The Journal of Positive Psychology, 5, 3-11. http:/ /dx.doi.org/10.1080/17439760903271116 